\title{
Diacronie
}

Studi di Storia Contemporanea

$N^{\circ} 7,3 \mid 2011$

«Spagna Anno Zero»: la guerra come soluzione

\section{Cultura de resistencia y guerra civil en la base naval principal de la República. Cartagena (1936-1939)}

Pedro María Egea Bruno

\section{OpenEdition}

Journals

Edición electrónica

URL: http://journals.openedition.org/diacronie/3434

DOI: 10.4000/diacronie.3434

ISSN: 2038-0925

Editor

Association culturelle Diacronie

Referencia electrónica

Pedro María Egea Bruno, « Cultura de resistencia y guerra civil en la base naval principal de la República. Cartagena (1936-1939)», Diacronie [En línea], № 7, 3 | 2011, documento 3, Puesto en línea el 29 julio 2011, consultado el 01 mayo 2019. URL : http://journals.openedition.org/diacronie/3434 ; DOI : 10.4000/diacronie.3434 


\title{
Diacronie
}

\section{3/}

\section{Cultura de resistencia y guerra civil en la base naval principal de la República. Cartagena (1936-1939)}

\author{
Pedro Ma EGEA BRUNO *
}

El fenómeno de la propaganda como expresión de persuasión colectiva está unido al nacimiento mismo de los enfrentamientos bélicos, convirtiéndose en un instrumento tan eficaz como las propias armas. Tras su empleo durante la I Guerra Mundial, será la guerra civil española su principal campo de experimentación. Para ello se emplearon todos los recursos disponibles: libros, folletos, octavillas, declaraciones a la prensa, emisiones radiofónicas, documentales, carteles, dibujos y pinturas. Se podrían añadir las ocupaciones del espacio público: mítines, desfiles de tropas y entierros de combatientes caracterizados. La rotulación de las calles, con nombres apropiados a la nueva realidad, también se convirtieron en apelaciones directas a la conciencia ciudadana. Lo mismo puede decirse de los refugios antiaéreos, transmutados en símbolos mudos de las agresiones franquistas.

\footnotetext{
Bienvenidos sean los cañones si, en las brechas que abren, florece el Evangelio.

Miguel de los Santos Díaz y Gómara, Obispo de Cartagena entre 1935 y 1949.
}

artagena es uno de los enclaves militares de mayor envergadura de la Península. Su peso resulta determinante en el origen, desarrollo y fin del conflicto bélico. Cabecera del Departamento Marítimo del Mediterráneo y sede de una importante base naval que alberga complejas instalaciones 
militares, desde el Arsenal a cuarteles de Marinería e Infantería de Marina, pasando por el fondeadero de submarinos, los servicios de Ingeniería Naval e Intendencia, la Escuela de Buzos y Submarinistas de la Armada, una relevante estación de radiotelegrafía e importantes depósitos de municiones y combustible. La base es sede operativa de las flotillas de destructores, submarinos y torpederos, junto con diversos barcos de transporte y salvamento. Será defendida por un impresionante despliegue artillero y por dos aeródromos militares: los de Los Alcázares y San Javier¹.

Iniciado el conflicto bélico se constituirá en la única base de la República. Acogerá también a una importante industria de guerra, la segunda en escala detrás de la catalana, donde destacará la Sociedad Española de Construcción Naval. El Gobierno de Largo Caballero -por decreto de 2 de enero de $1937^{2-}$ potenció su importancia, convirtiéndola en un poder autónomo, prácticamente una provincia, cuyos límites territoriales quedaban bien establecidos: Al Norte el río Segura, al Oeste, el ferrocarril de Orihuela a Murcia, llegando al empalme con el de Cartagena y las sierras de Carrascoy y Almenara, hasta el Cabo de Cope. Al Sur y al Este, el Mar Mediterráneo, bordeando el límite de las aguas jurisdiccionales. En total se le anexionaron 21 pueblos de las provincias de Murcia y Alicante. Su jefe -que podía pertenecer a cualquiera de las armas- dependía directamente del ministro de la Guerra y centralizaba los resortes del mando en el orden civil, político y militar3.

\section{El frente de papel}

La prensa sufrió una importante mutación. Las cabeceras de los partidos derechistas desaparecieron o fueron reconvertidas en órganos de las opciones más avanzadas ${ }^{4}$. En la localidad, Cartagena Nueva, portavoz de la Unión Patriótica, quedó bajo control del Frente Popular y - desde el 10 de febrero de 1937 - de la CNT. Surgieron nuevos periódicos. El 18 de enero de 1937 salió a la calle Amanecer, emisario del acorazado Jaime I. El 31 de marzo, Crescencio Bilbao - diputado a Cortes y

1 Vid. MARTÍNEZ LEAL, Juan, República y Guerra Civil en Cartagena (1931-1939), Murcia, Universidad de Murcia-Ayuntamiento de Cartagena, 1993, pp. 157-164.

$2 \quad$ Gaceta de la República, 3 de enero de 1937, pp. 34-35.

3 Vid. MARTÍNEZ LEAL, Juan, «El esfuerzo de guerra de Cartagena, Base Naval de la República», en GÓMEZ OLIVER, Miguel Carlos y RUIZ-MANJÓN CABEZA, Octavio (coords.), Los nuevos historiadores ante la Guerra Civil española, vol. 1, Granada, Diputación Provincial, 1990, pp. 21-44; EGEA BRUNO, Pedro $\mathrm{M}^{\mathrm{a}}$, La guerra invisible. Espionaje, sabotaje y contrarrevolución en la base naval principal de la República. El expediente Arturo Espa Ruiz. En prensa, 2011.

$4 \quad$ Vid. MATEOS FERNÁNDEZ, Juan Carlos, Bajo el control obrero. La prensa diaria en Madrid durante la guerra civil (1936-1939), Madrid, Universidad Complutense, 2000. FIGUERES ARTIGUES, Josep M., Periodismo en la guerra civil, Barcelona, Publicacions Abadía Monserrat, 2010. 
subcomisario general de Guerra - anunció la aparición para el 3 de abril de $L a$ Armada, que sería dirigido por Bruno Alonso, comisario de la flota. Desde el 30 de mayo con ellos compitió Venceremos, heraldo del Comité Comarcal del Partido Comunista, coordinado por el también parlamentario Francisco Félix Montiel. Finalmente, el 8 de junio de 1938 se publicó Unidad, expresión provincial del Partido Comunista. A partir el 2 de febrero de 1937 La Tierra - el antiguo vocero de la derecha republicana - reapareció con el subtítulo de Diario de la Juventud, regentado por la Juventud Socialista Unificada (JSU). Su redacción y administración se ubicó en el Gran Hotel, que había sido expropiado. El 9 de septiembre, cambió su nombre por el de Ofensiva, Semanario de la Juventud. Llegó a tener una presencia continuada, por lo menos hasta el 25 de marzo de 19385.

El Semanario de la Juventud fue el mejor ejemplo de prensa de combate, incubada al calor de la contienda, donde palabra y acción se fundían ${ }^{6}$. En su misma redacción se instaló el centro de reclutamiento de los denominados Batallones Juventud. Ocupó un lugar de relieve en la batalla propagandística. En sus páginas se alentaba a la continua movilización con una consigna reveladora de la mentalidad reinante y de un claro posicionamiento político: «iLos hombres al frente y las mujeres a la producción». Las invocaciones eran directas: «iLa Patria está en peligro! [...] iNo temas ni te duela abandonar el instrumento de trabajo ni el estudio para empuñar con hombría el fusil o la ametralladora! iLa Patria te necesita! Nuestras muchachas, tu hermana, tu amiga, tu compañera o tu novia, cubrirá con alegría el puesto que tú dejas vacío / iNo te importe nada! Tu porvenir, tu cultura, tu alegría, incluso tu propia vida, se decide en los campos de batalla».

La misma tónica ofrecían los llamamientos a las chicas: «Incorporación de las muchachas al trabajo. / Hay que seguir el ejemplo de las buenas muchachas de Cartuchería [Fábrica de Cartuchería instalada en el Parque de Artillería], que han elevado extraordinariamente la producción». Se las convocaba también para ocupar puestos en la dirección de la JSU: «Un gran número de jóvenes socialistas unificados se va a movilizar voluntariamente. Los puestos dirigentes de nuestra organización no pueden quedar abandonados. Nuestra Juventud debe continuar en la retaguardia llevando la voz de la heroica joven generación de las trincheras, educando e incorporando nuevas masas de jóvenes para que sean bravos soldados de nuestro Ejército Popular. / Entonces nuestras muchachas deben aprestarse a sustituirnos en

5 MÍNGUEZ LASHERAS, Francisco, La prensa cartagenera en la guerra civil, Cartagena, Asociación Belenista de Cartagena-La Unión, 2000.

6 GRANDELA, José Manuel, Balas de papel. Anecdotario de propaganda subversiva en la Guerra Civil española, Barcelona, Salvat, 2002. 
estos puestos. Nuestros Radios deben ocuparse de la rápida educación cultural y política de las muchachas».

El papel de aquellas jóvenes fue determinante en la agitación de la retaguardia, manteniendo la moral frente a todas las derrotas: «Las calles céntricas de Cartagena se llenaron de grupos atentos alrededor de nuestras bravas muchachas. Oyendo la voz vibrante y fervorosa de nuestras muchachas. Ellas se han lanzado a las calles a luchar contra la depresión, contra el pesimismo, contra la desmoralización, la baba asquerosa de la quinta columna. Han ido a las fábricas, han hablado al pueblo, a los obreros, a los jóvenes, a las mujeres...»7.

La urgencia social de los noticiarios no estuvo reñida con la calidad. El caso más destacado fue el de Cartagena Nueva, que contó con la dirección de Ramón Perelló, conocido músico y letrista de coplas, algunas de indudable arraigo popular: Mi jaca, La bien pagá, Falsa monea, Soy minero... ${ }^{8}$. Al frente del periódico dará suelta a su ingenio más corrosivo para ridiculizar a los generales golpistas y a sus cómplices. Bajo la entradilla de Gazpacho Andaluz, desfilarán Franco, Mola, Doval, Aranda, Pérez Madrigal, Cardenal Segura, García Sanchiz, Alejandro Lerroux, Pemán, Luca de Tena y González Marín. Un ejemplo bastará:

\section{Comandante Doval}

Bajo er só de Andalusía

-porvo y sueño- a Asturias van.

Caminan der Moro a Oviedo

Los seviles de Dová.

A los piés de un limonero

que su sombra les brindó

descansan -sobre los ojos

los tricornios de charó-

$\mathrm{Y}$ un gitano canastero

que los vio en er limoná

contemplando ar limonero

lanzó ar viento este cantá:

-Limonero, limonero,

orguyo der limoná,

antes de darles tu sombra 
te debiste de secá...

Limonero, limonero,

orguyo der limoná...

Ya se van llenos de sueño,

Ya se van muertos de sé.

¡Arroyuelo der camino,

a su paso, secate...!

Luchan, bravos, los mineros

-mártires del Ideá-

dando er pecho a los fusiles

de los picos de Dová.

iAy, minerito, minero,

clavé de la Libertá...!

Vuerven de Asturias ar Moro

bajo er só de media tarde

-los ojos llenos de fuego,

las manos llenas de sangre.

A los pies der limonero,

mirándolos de pasá

er gitano canastero

lansa ar viento este cantá:

-Limonero, limonero,

orguyo del limoná,

antes de darles tu sombra

te debiste de secá...

Limonero, limonero

orguyo der limoná... 
La cartelística fue otro de los medios utilizados, tal vez de los más logrados en la propaganda republicana. Como señalaba J. Renau, uno de sus mejores cultivadores, un cartel era un grito pegado a la pared. La modalidad tuvo escaso desarrollo en Cartagena. Hemos encontrado un ejemplar aislado y de resolución técnica no muy afortunada. Se debe a M. Bayona, está editado por el Comité de Cultura y Propaganda del Frente Popular Antifascista de la localidad y recoge uno de sus lemas más reiterados: «La Victoria se obtiene con disciplina, trabajo y adhesión al Gobierno»9.

\section{Despedir a los héroes: la reafirmación identitaria}

El 24 de julio de 1936 tuvo lugar el entierro de Antonio García Fuentes, primer miliciano cartagenero muerto en acto de guerra. Militante de la CNT, formaba parte de la milicia popular que se organizó en la ciudad para la toma de Hellín, en la vecina provincia de Albacete ${ }^{10}$. Para solemnizar el sepelio cerró el comercio y la industria: «La salida del cadáver fue un acto imponente, difícil de poder definir, por el público congregado, tan numeroso que se puede decir que estaba allí Cartagena entera, y con los puños en alto, fue recibido el cadáver, dándose varios vivas que fueron contestados unánimemente».

Se escenificaron las referencias ideológicas requeridas: el ataúd fue cubierto con la bandera anarquista, en la comitiva formaban las milicias de las Juventudes Comunista, Socialista, CNT y Unión Republicana, presidían autoridades civiles y militares y se contaba con una representación del Frente Popular y de los partidos políticos que lo integraban. Se partió del antiguo Hospital de la virgen de la Caridad - renombrado, fruto de la realidad vigente, Policlínica Roldan -, donde se había emplazado la capilla ardiente, y se recorrieron las calles principales de la ciudad, hasta llegar al Ayuntamiento, en la ahora llamada plaza de García Hernández, héroe seminal de la República. Allí, en una prolongada despedida, se desfiló frente al féretro, se cantó $L a$ Internacional con los puños en alto y se contextualizó aquella muerte: «... El desfile duró varias horas y al terminar un compañero de la CNT habló por el micrófono dando las órdenes oportunas para la disgregación de la comitiva y dedicó un pequeño

9 Vid. RENAU, Josep, Función social del cartel, Valencia, Fernando Torres, 1976; JULIÁN GONZÁLEZ, Inmaculada, El cartel republicano en la guerra civil española, Madrid, Ministerio de Cultura, 1993; UNIVERSIDAD DE VALENCIA, Imágenes en guerra, Valencia, Universidad de Valencia, 1998; CABAÑAS BRAVO, Miguel, Joseph Renau, arte y propaganda en guerra, Madrid, Ministerio de Cultura, 2007; BRIHUEGA, Javier, PIQUERAS, Norberto, Joseph Renau, compromiso y cultura, Valencia, Universidad de Valencia, 2007; ALVARADO LÓPEZ, M ${ }^{\mathrm{a}}$ Cruz, ANDRÉS DEL CAMPO, Susana de, «La conciencia de papel: El cartel social en la guerra civil española», en $A$ Distancia, $\mathrm{n}^{0} 1,2008$, pp. 112-121.

${ }_{10}$ Vid. DIMAS BALSALOBRE, Floren, «La batalla de Hellín», en Murcia Histórica, en prensa. 
recuerdo a la víctima del fascismo, que en su locura ha querido llevar a España a una hecatombe para aplastar a los proletarios, haciéndose dueños de las riendas del poder, lo que no ha conseguido por haber frente a ellos un pueblo consciente que ha sabido dar una lección a esos facinerosos...».

Hubo otra propaganda espuria, que mercantilizó el dolor y el desamparo de la familia. Tal fue el sentido de la carta que se vio forzada a suscribir la viuda del miliciano y que la prensa publicó sin comentarios: «Sres. Sub-Directores de El Ocaso S.A.Cuatro Santos 41 y 43.- Cartagena. / Muy Sres. Míos: Tiene por objeto la presente, testimoniarles mi gratitud, por el hecho de que hoy me han sido abonadas por esa Compañía la cantidad de SEISCIENTAS CINCUENTA pesetas, por renuncia a entierro y accidente acaecido a mi difunto esposo don Antonio García Fuentes habitante en la calle de D. Gil 20. Aumentando aún más mi agradecimiento el saber por el artículo $7^{0}$ de su Reglamento que, cuando la muerte se produce por alteración de orden público, los asociados pierden sus derechos. / Este hecho demuestra que esa Compañía atiende a sus asociados en cualquier caso en que se produzca la defunción, por lo que es una satisfacción para mí que se publique la presente, al objeto de que todos los asociados sepan una vez más, el celo de esta Sociedad en el cumplimiento de sus deberes. / Reiterándoles mis gracias, que a sus órdenes suya afma. s.s.q.e.s.n. / Por no saber firmar la viuda.- Isabel Díaz»11.

Mayor trascendencia tuvo el entierro de las bajas ocasionadas por la explosión del acorazado Jaime I, que el ministro de Defensa Nacional - Indalecio Prieto «consideró a todos los efectos como un acto de guerra» ${ }^{12}$. Tuvo lugar el 18 junio de 1937 y registró una asistencia muy superior: «El público invade totalmente las calles por las cuales desfiló el entierro, que ha constituido la más imponente manifestación de duelo que se recuerda desde hace muchísimos años» ${ }^{13}$. La dimensión de la tragedia y el carácter de las víctimas explican que la representación oficial resultase más nutrida, empezando por el subsecretario de Marina, Antonio Ruiz; el comisario político de la flota, Bruno Alonso; el jefe de la misma, Miguel Buiza y el jefe de la base, Valentín Fuentes. No faltó la presencia de los sindicatos y partidos políticos, ni los himnos, interpretados por la banda del Regimiento Naval Núm. 1.: La Marcha fúnebre proletaria, El Komintern, La Internacional, Banderas rojas y el Himno de Riego. El contrapunto estuvo representado por la improvisación, no estando preparadas las fosas necesarias para acoger a aquellos cuerpos, 50 en total.

$11 \quad$ El Noticiero (Cartagena), 24 de julio de 1936.

12 Vid. EGEA BRUNO, Pedro $\mathrm{M}^{\mathrm{a}}$, «Contribución al estudio de la flota republicana durante la guerra civil: la voladura del acorazado Jaime I en el puerto de Cartagena», Murgetana, $\mathrm{n}^{\circ} 93$, 1996. HERNÁNDEZ CONESA, Ricardo, IBÁÑEZ RUBIO, Santiago, «El acorazado Jaime I», Cartagena Histórica, monográfico $\mathrm{n}^{0}$ 4, 2003.

$13 \quad$ Venceremos (Cartagena), 19 de junio de 1937. 


\section{La calle: borrar el pasado, rotular el presente, alumbrar el futuro}

Las calles fueron rotuladas con títulos inequívocos. Un hecho correlativo a los procesos revolucionarios y, en el caso de España, manifestación de la hagiofobia que impera en el bando republicano ${ }^{14}$. El primer cambio tuvo lugar el 31 de julio de 1936, cuando el Ayuntamiento decidió que «... en lo sucesivo la Plaza del General Cabanellas se denomine Plaza de Antonio García Fuentes, primer miliciano cartagenero muerto en defensa de la República»15. Fue el comienzo de todo un proceso de renovación, que se prolongó hasta agosto de 1938 y que no estuvo exento de precipitación. Hubieron de revisarse acuerdos, al superponerse las denominaciones. Esa misma vehemencia tropezó con lo irrealizable. Ocurrió con una determinación del Consejo Municipal de 9 de agosto de 1938: «... el nombre de Santiago Rusiñol se le ha dado a la Plaza de San Leandro, plaza que no existe en Cartagena, pues la que llevaba tal denominación desapareció al hacerse la apertura total de la calle de Gisbert en $1893 \ldots{ }^{16}$.

La exaltación de los combatientes fue un recurso frecuente. El 21 de agosto de 1936 una calle de las Casas Baratas pasó a ser del Capitán Fernando Condés, justamente en la que habían vivido su viuda e hijo. En el barrio de La Concepción, la calle del Rosario cambió a Héroes del Ferrándiz, el sargento Bascuñana destronó al general Barceló y la calle Mayor fue ahora del comandante José Aliaga. En Santa Lucía, el fogonero Dionisio Marchante ocupó el lugar de Mínguez, un alcalde de la dictadura primorriverista.

Las nuevas denominaciones traducían las opciones ideológicas en presencia, reflejadas en referencias de la clase trabajadora. Así Anselmo Lorenzo sustituyó a Villalba la Larga y el Guerrillero Buenaventura Durruti al General Ordoñez. A todo ello se unió el deseo de borrar un pasado representado por designaciones religiosas, militares y nobiliarias. De este modo, se variaron los marbetes de las plazas de La Merced y San Francisco por los de Méjico y Dolores Ibárruri Pasionaria, mientras el Marqués de Valmar era desplazado por Eliseo Reclús. En el Barrio de Peral, Buenaventura Durruti ocupó el lugar de San Pedro y San Miguel dejó paso al Primero de Mayo, y en Los Dolores, la vía de León XIII fue renombrada del Capitán de la Cotera.

14 Vid. DORION, Henri, «La toponyme, complice involontaire de la politique», en Internacional Congreso of Onomastic Sciences, Aberdeen, 1998; CUADROS, Ignasi, «Els topònims municipals de la $7^{\text {a }}$ Regió durant la guerra civil i la revolució de 1936», en Dovella, $\mathrm{n}^{\circ}$ 33, 1989, pp. 57-59; INGLÉS I RAFECAS, Joseph Maria, «La nominació dálguns topònims penedesencs durant la Segona República i la Guerra Civil», en Miscel-lània Penedesenca, $\mathrm{n}^{0} 17$, 1993, pp. 403-412; TORT, Joan, «Los cambios de nombre de los municipios durante la revolución y la guerra civil españolas (1936-1939). El caso de Cataluña», en Scripta Nova. Revista electrónica de geografía y ciencias sociales, vol. VIII, $\mathrm{n}^{0} 133,2003$.

15 Archivo Municipal de Cartagena [AMC], Acta Capitular [AC], 31 de julio de 1936.

$16 \quad$ AMC. AC, 9 de agosto de 1936. 
En alguna ocasión fue preciso aclarar determinadas inscripciones, como la de María Cruz, a la que se añadió La Libertaria. A veces el denostado pasado apenas tenía un año, como fue el caso del destituido presidente Alcalá Zamora, cuya plaza fue ocupada por el socorrido Durruti, desapareciendo también del Algar. Llegado el momento hubo de echarse mano de efemérides históricas, de luchadores por la libertad de todos los tiempos - como los comuneros de Castilla - y de glorias patrias de las letras y de las artes.

\section{ROTULACIÓN DE CALLES Y PLAZAS APROBADAS EN LA SESIÓN MUNICIPAL DE 9 DE AGOSTO DE 1938}

Sagasta
Niño
Hierro
Horno
San Fulgencio
Conducto
San Roque
Salitre
La Palma
San Rafael
Canales
Baños del Carmen
Cuatro Santos
Condesa de Peralta
Nueva
Concepción
Callejón del Cura
San Crispín
Herrero
Don Matías
San Agustín
Montanaro
Marango
Luis Angosto
Callejón del Chiquero
Rosario
Pozo
San Cristóbal Corta
Adarve
Morería baja
San José

\section{CALLES}

$$
\begin{gathered}
\text { Maldonado } \\
\text { Murillo } \\
\text { Escultor Barral } \\
\text { Joaquín Dicenta } \\
\text { Victorio Macho } \\
\text { Diego de Padilla } \\
\text { Altaras } \\
\text { Sorolla } \\
\text { Velázquez } \\
\text { Mariana de Pineda } \\
\text { María de Padilla } \\
\text { Dantón } \\
\text { Comuneros de Castilla } \\
\text { Juan de Lanuza } \\
\text { Capitán Farando } \\
\text { Casas Salas } \\
\text { José Villaverde } \\
\text { María Cruz (Libertaria) } \\
\text { Francisco Asín } \\
\text { Isaac Puente } \\
\text { Manzo } \\
\text { Lina Odena } \\
\text { Fernando de Rosas [sic] } \\
\text { Miguel de Cervantes } \\
\text { Trafalgar } \\
\text { Seis de octubre } \\
\text { Fermín de Zaya } \\
\text { Teniente Castillo } \\
\text { Doctor Jaime Vera } \\
\text { Francisco Lairet [sic] } \\
\text { María Durán }
\end{gathered}
$$




Mariano Sanz
San Agustín
José María Artés
Cuartel del Rey
Par
San Leandro
Hospital
Tronera
Risueño

\section{PLAZAS}

\author{
Primero de Mayo \\ Francisco Ascaso \\ Milicianos Cartageneros \\ Zampirain \\ Quevedo \\ Santiago Rusiñol \\ Pérez Galdós \\ Dionisio Marchante \\ Gravina
}

La marea renovadora alcanzó a los topónimos de barrios y diputaciones, al objeto de suprimir del nomenclátor todos los sanes. De este modo Los Dolores se transformaron en Trifón Medrano, Santa Lucía en Francisco Ferrer Guardia, San Antonio Abad en La Libertad, La Concepción en Lina Odena, Miranda en Mariana Pineda, Santa Ana - con poca fortuna - en Leopoldo Alas, La Magdalena en Aída de la Fuente, Canteras en García Lorca, La Palma en Fermín Salvoechea, Los Barreros en Ángel Pestaña, el paraje de San Isidro en Buenaventura Durruti y el de La Aparecida en Caserío de Ascaso. Aquellas enunciaciones fueron borradas por el régimen franquista y sustituidas por las que le eran afines.

\section{Los refugios: lugares de memoria}

Cartagena se convierte en mención obligada del bando republicano. Desde ser la única base naval a erigirse en puerto trascendental para el desembarco de las armas soviéticas, sin olvidar su conversión en el segundo núcleo - detrás de Cataluña- de producción bélica. Se veía envuelta, además, en la aureola de haber resultado clave en la desarticulación de la sublevación franquista: "Cartagena ha salvado a España y a la República», era noticia aireada con frecuencia en la prensa nacional ${ }^{17}$.

Todo explica que fuera una de las ciudades más castigadas por la aviación enemiga. Desde el 18 de octubre de 1936 aparece como objetivo preferente de la escuadra ítalogermana al servicio de Franco. Sufrirá un total de 117 bombardeos, un poco menos que Barcelona, pero la capital catalana albergaba un millón de habitantes y el enclave levantino algo más de cien mil. En total 233 víctimas mortales, centenares de heridos y 336 fincas enteramente derruidas, un tercio de los inmuebles registrados ${ }^{18}$.

\footnotetext{
17 Cfr. El Día (Alicante), 3 de agosto de 1936 y La Vanguardia (Barcelona), 4 de agosto de 1936.

18 MARTÍNEZ LEAL, Juan, República y Guerra Civil en Cartagena (1931-1939), Murcia, Universidad de Murcia-Ayuntamiento de Cartagena, 1993, pp. 315-323.
} 
Las vías afectadas estaban claramente alejadas de los objetivos militares, lo que refleja el deseo de masacrar a la población civil, especialmente a partir del salto cualitativo que supuso el ataque del 25 de noviembre de 1936, una de las agresiones más salvajes, conocido como el bombardeo de las cuatro horas, realizado entre las 17,30 y las 21,30 horas por 20 Junker de la Legión Cóndor, que arrojaron 25 toneladas de bombas y provocaron numerosos destrozos materiales y 16 víctimas mortales ${ }^{19}$.

El cambio operado será señalado con entera claridad por la prensa local: «Hasta el pasado miércoles, las incursiones de la aviación facciosa en Cartagena tuvieron un objetivo militar, guerrero: bombardear los buques y el Arsenal; pero el último bombardeo de los aviones rebeldes no tuvo otra finalidad que asesinar ciudadanos indefensos, pacíficos, ya que sobre la ciudad cayeron bombas y bombas explosivas e incendiarias, incluso en lugares hasta ahora respetados por todos los tratados internacionales, y si esto no fuera suficiente, respetados por toda conciencia sana y noble. Nos referimos a los hospitales, pues al nuestro alcanzó el fanatismo guerrero de los rebeldes, causando víctimas, como igualmente las produjo en un tren de línea de Cartagena a La Unión, y desde luego en varios sitios de la ciudad y barrios extramuros» ${ }^{20}$.

La respuesta fue la construcción de refugios antiaéreos ${ }^{21}$. Desde el 6 de octubre de 1936 el ministro de Hacienda - Juan Negrín - había abierto una línea de crédito para el pago de jornales y materiales pertinentes para las obras de defensa de los núcleos urbanos $^{22}$. Aquellas cantidades se agotaron enseguida y hubo que reponerlas el $17 \mathrm{de}$ noviembre, ahora citando expresamente a Cartagena: «Las necesidades de la campaña emprendida para combatir el movimiento subversivo imponen, con carácter urgente, que por el Consejo Mixto de Trabajos de Fortificación se proceda a dotar a las plazas de Valencia y Cartagena de las fortificaciones y defensas antiaéreas precisas para su mayor seguridad...»23. Fue un pozo sin fondo, y la dotación de nuevos recursos hubo de renovarse en dos ocasiones: 23 de febrero y 6 de septiembre de 1937.

Las primeras medidas adoptadas consistieron en la protección de los centros que se consideraban esenciales, como el de la Delegación Gubernativa, que lo fue en diciembre de 1936, y el de la Compañía de Teléfonos, en enero de 1937: «La necesidad de conservar el enlace telefónico en todo momento no sólo entre los diversos organismos civiles y militares de la Plaza, sino entre el Gobierno de la República y el mando, hizo se pensara

19 PUCHOL FRANCO, Miguel S., GARCÍA TOUS, Francisco Javier, «Bombardeos aéreos sobre Cartagena en 1936: el bombardeo de las cuatro horas», Cartagena Histórica, $\mathrm{n}^{\circ} 3,2003$, pp. 5-19.

$20 \quad$ Cartagena Nueva, 26 de noviembre de 1936.

21 Vid. BESOLÍ MARTÍN, Andreu, «Los refugios antiaéreos de Barcelona: Pasado y presente de un patrimonio arcano», in Ebre 38, no 2, 2004, pp. 181-202.

$22 \quad$ Gaceta de Madrid, 7 de octubre de 1936, p. 217.

$23 \quad$ Gaceta de Madrid, 19 de noviembre de 1936, p. 722. 
desde el primer momento en este edificio; pero esta necesidad se convirtió en deseo vehemente de las autoridades y los vocales del Subcomité de Defensa Antiaérea, ante la conducta no ya ejemplar sino estoica del personal de este centro telefónico, que en los repetidos bombardeos sufridos no ha abandonado el cuadro ni un instante» 24 .

La construcción de los refugios fue fruto de un meditado análisis, formando parte de un plan general, quedando estratégicamente situados. La ciudad fue organizada en sectores, «... división que se hacía atendiendo tanto a su población y extensión como a la naturaleza del terreno donde situar la zona de refugio y facilidad de acceso a él...». Fueron aprobados el 14 de febrero de 1937 por la Subsecretaría del Ministerio de la Guerra, señalando que debía «... hacerse un estudio de los mismos, para que a medida que sea posible, se vayan redactando los oportunos presupuestos, a fin de que los habitantes civiles y militares de Cartagena, tan castigados por la aviación rebelde, tengan los medios de protección necesarios, y además de llenar los cometidos necesarios, servirán para aumentar y garantizar, ahora y en el futuro, el valor militar de la plaza» 25.

Se aprovecharon -cuando fue posible- las colinas presentes en la topografía local y a veces el fortuito hallazgo de galerías subterráneas abiertas en un pasado ignoto, como las halladas en el Molinete y bajo la iglesia de Santa María la Nueva. Fueron objeto de una cuidada construcción. Disponían de dos entradas, para sortear la posibilidad de su simultánea obstrucción por el derrumbamiento de los edificios cercanos. Reflejaban el temor a las agresiones que se podían esperar del fascismo internacional, como el gas tóxico, y contaban con instalaciones de ventilación y regeneración de aire. Estaban pensados para albergar entre 500 y 3.500 personas, aunque no todas podían permanecer sentadas en los bancos corridos de que eran provistos. El coste unitario por alojado se estimaba en 424 pesetas. Los proyectos fueron firmados por el arquitecto municipal Luis Durán de Cottes y Martínez. Firmemente comprometido con la causa republicana, contribuirá en suscripciones a favor de las Milicias Populares y figurará como vicepresidente del comité local de la asociación Amigos de la Unión Soviética, en la que Carmen Conde constaba como vocal ${ }^{26}$. Como tantos otros profesionales, será separado del servicio por el régimen franquista ${ }^{27}$.

La sensación de seguridad no mejoró. El recinto urbano será abandonado cada atardecer, «... dando la total sensación de una ciudad muerta, de una ciudad abandonada, de un pueblo cohibido y amedrentado» ${ }^{28}$. El pánico resultó irreprimible y se suscitó en cada nueva alarma. Lo señalaba Bruno Alonso a Indalecio Prieto en carta del 24 de enero

\footnotetext{
$24 \quad$ AMC. Caja 944. Exp. 1. Proyectos de Refugios. 1937.

$25 \quad$ AMC. Caja 944. Exp. 2.

26 Cartagena Nueva, 28 de octubre de 1936.

$27 \quad$ Boletín Oficial del Estado, 10 de agosto de 1940, p. 5.567.

$28 \quad$ Cartagena Nueva, 15 de julio de 1938.
} 
de 1938: «El sábado voló sobre Cartagena un avión faccioso Heinkel, que debía ser de reconocimiento, sacando, sin duda, fotografías de la Plaza. / Se rompió el fuego contra él cuando se percibió que era enemigo y se marchó. Hubo en la población ocho muertos, niños la mayor parte, atropellados por los mayores, cobardes que se precipitaron a los refugios ${ }^{29}$. No sorprende que la evacuación de la infancia se contemplase como prioritaria. Fue así como el maestro Eduardo Haro Ibars marcho a la URSS acompañando a una expedición de menores ${ }^{30}$. Por lo demás, el Hospital se trasladó a las dependencias a medio terminar de Los Barreros y la ciudad quedó atendida con una Casa de Socorro, finalmente instalada en las Escuelas Gradadas, en las inmediaciones de los refugios recién construidos.

29 Archivo Histórico Nacional. Sección Guerra Civil (Salamanca) [AHN-SGC]. Archivo de Bruno Alonso González. ES.37274.AGGCE/9. Correspondencia con Indalecio Prieto (19371938).

$3^{3}$ Vid. EGEA BRUNO, Pedro $\mathrm{M}^{\mathrm{a}}$, La enseñanza primaria en Cartagena durante la II República y la Guerra Civil (1931-1939), Cartagena, Aglaya, 2006. 


\section{La proyección exterior de la barbarie: Cartagena en la Sociedad de Naciones}

La propaganda republicana dedicó especial atención a los bombardeos aéreos de las poblaciones de retaguardia, que segaron un total de 11.000 vidas ${ }^{31}$. Eran pruebas irrefutables del carácter criminal del enemigo y violaban la Convención de La Haya de 1923. La campaña arrancó con los primeros ataques sobre Madrid, entre noviembre de 1936 y enero de 1937, y alcanzó uno de sus momentos culminantes con la devastación de Guernica por parte de la Legión Cóndor a finales de abril de $1937^{32}$.

La finalidad era demostrar la participación de las potencias nazifascistas al lado del bando franquista. El origen de semejante dinámica se remontaba a septiembre de 1936 con la constitución - a propuesta de Francia - de un denominado Comité de No Intervención o Comité de Londres, que buscaba evitar la mediación extranjera en la guerra civil española y que perjudicó gravemente a la causa de la República33. No andaba descaminado Hugh Thomas cuando escribía que aquel organismo «cultivaría desde el equívoco hasta la hipocresía» 34.

Resultó clarificador el torpedeamiento realizado el 22 de noviembre de 1936 por parte de submarinos italianos sobre la escuadra republicana anclada en el puerto de Cartagena, causando averías graves al crucero Miguel de Cervantes, que sufrió cinco bajas y estuvo en reparaciones hasta finales de abril de 1938. El ministro de Marina y Aire - Indalecio Prieto - denunció la connivencia desatada: «No ha sido preciso esperar a que los gabinetes de Berlín y Roma reconociesen al Gobierno Franco - lo habían hecho el 18 de noviembre - para advertir que los buques militares de ambas naciones, que en número crecidísimo pululan desde julio último por nuestras costas, realizaban acciones reñidas con los deberes que impone la neutralidad, dedicándose a auxiliar a las escasas unidades de la escuadra española que quedaron en poder de los rebeldes. La flota republicana ha sido constantemente espiada por dichos buques extranjeros que, en estratégica posición, podían darse cuenta perfecta de los movimientos de aquélla, los cuales eran al instante conocidos de los barcos rebeldes. Además, hay señales bastante claras para asegurar que, a base de idéntico servicio de

31 SOLÉ, Joseph Ma, VILlAROYA, Joan, España en llamas. La Guerra Civil desde el aire, Madrid, Ediciones Temas de Hoy, 2003, pp. 313-316.

32 SOUTHWORTH, Herbert R., La destrucción de Guernica. Periodismo, diplomacia, propaganda e historia, Barcelona, Iberia de Ediciones y Publicaciones, 1977.

33 AVILÉS FARRÉ, Juan, Pasión y farsa: franceses y británicos ante la guerra civil española, Madrid, Eudema, 1994; MORADIELLOS GARCÍA, Enrique, La perfidia de Albión. El Gobierno británico y la Guerra Civil española, Madrid, Siglo XXI, 1996.

34 THOMAS, Hugh, La Guerra Civil española, Madrid, Diario 16, 1976, p. 368. 
espionaje, venían efectuándose los ataques aéreos que han sufrido algunas de nuestras ciudades del Mediterráneo». Aportaba datos concretos, como los alusivos a Cartagena: «Al regresar del Cantábrico la flota y salir de Cartagena el Méndez Núñez y tres cruceros para unirse a ella, fue comunicada esta salida a los rebeldes por un destructor alemán, que se hallaba a la entrada del referido puerto. A partir de entonces se ha acusado frecuentemente la presencia de un buque de guerra alemán a la entrada de Cartagena, sin duda con el encargo de comunicar a diario la situación de nuestros barcos» 35 .

No se titubeaba al señalar la autoría del atentado. El parte oficial facilitado implicaba a una flota extranjera, «... ya que los elementos facciosos no han dispuesto en ningún momento de buques de esta clase ni han podido construirlos...». El 10 de diciembre de 1936 se hizo público el informe del cartagenero Remigio Verdia Solé, capitán de corbeta y jefe de la flotilla de submarinos: «Examinados los restos del torpedo, se observa que pertenecen a un torpedo Whiteat [sic], de 533, construido en Fiume (Italia), de dimensiones exactamente iguales al tipo reglamentario de nuestra Marina, pero con la particularidad de no pertenecer a ella, por ser tornillos de metal los que empleamos en nuestros torpedos para una cabeza de combate y cámara de aire, siendo de acero los tornillos de este torpedo. / El calibre de los tubos de los submarinos tipo $B$ es de 450 milímetros y es de 533 milímetros el diámetro del torpedo hallado. Este ha sido pues lanzado por un submarino extranjero, probablemente italiano, ya que tiene esta procedencia el torpedo que lanzaron» 36 . Se trataba, en efecto, del submarino legionario Torricelli, rebautizado con el nombre de General Mola.

Las agresiones de noviembre de 1936 sobre Cartagena fueron difundidas por el Ministerio de Estado, a cuyo frente se encontraba un socialista de izquierdas, Julio Álvarez del Vayo ${ }^{37}$. Bajo su inspiración se editó un folleto trilingüe - castellano, francés e inglés - titulado Cartagena víctima del fascismo internacional. La publicación formaba parte de una estrategia bien diseñada, que trataba de demostrar la ineficacia del Comité de No Intervención. Sobre una realidad innegable, no deja de convertirse en instrumento de propaganda, magnificándose la agresión ${ }^{38}$.

$35 \quad$ La Vanguardia (Barcelona), 24 de noviembre de 1936.

$36 \quad$ La Vanguardia (Barcelona), 10 de diciembre de 1936.

37 Vid. PIZARROSO QUINTERO, Alejandro, «La Guerra Civil española, un hito en la historia de la propaganda», El Argonauta, n 2, 2005; RODRÍGUEZ GUTIÉRREZ, Cristina, «Julio Álvarez del Vayo y Olloqui ¿Traidor o víctima?», Espacio, Tiempo y Forma. Serie V. Historia Contemporánea, $\mathrm{n}^{0}$ 16, 2004, pp. 291-308. Su trayectoria política ha sido objeto de toda clase de controversias RADOSH, Ronald, HABECK, Mary R., SEVOSTIANOV, Grigory (eds.), España traicionada. Stalin y la Guerra Civil, Barcelona, Planeta, 2002.

38 GARCÍA FERNÁNDEZ, Hugo, "Seis y media docena: Propaganda de atrocidades y opinión británica durante la Guerra Civil Española», en Hispania, no 226, 2007, pp. 671-692. GARCÍA FERNÁNDEZ, Hugo, Mentiras necesarias: la batalla por la opinión británica durante la guerra civil, Madrid, Biblioteca Nueva, 2008. 
En el opúsculo se unía el torpedeamiento del Miguel de Cervantes y la incursión aérea de las cuatro horas: «En la ciudad de Cartagena varios barcos de nacionalidad extranjera; unos cuantos submarinos fascistas; un grupo de aeroplanos al servicio de la reacción internacional, en deliberada complicidad, cometieron hace pocos días la más inhumana crueldad». Las imágenes reproducían los efectos del atentado sobre los edificios civiles, prestando especial atención a los destrozos causados en el hospital. Había deliberado interés en demostrar que la agresión llevaba la firma de las potencias nazi fascistas que, de este modo, vulneraban los acuerdos del Comité de Londres. De ahí, la reproducción de tornillos y restos de metralla de los torpedos italianos. Las fotografías buscaban impactar en la conciencia de las democracias occidentales y a ese intento respondían las láminas de cadáveres destrozados, cuyo realismo se acentuaba con el fotomontaje, ubicándolos entre montones de escombros, en los escenarios más dramáticos de la agresión o, incluso, introduciendo a Franco con una frase atribuida: «Una bomba sobre un Hospital de Sangre significa a veces más que una victoria». El fascículo encerraba una lectura épica y cabal. Cartagena aparecía como «... un ejemplo más, entre los muchos que España ofrece hoy, de sufrimiento, de dignidad, de capacidad de resistencia. / Porque el Pueblo de Cartagena, tras de la terrible agresión, supo rehacerse, afirmando su voluntad de triunfo sobre el fascismo español y extranjero».

El 27 de noviembre - dos días después del bombardeo de las cuatro horas - el gobierno solicitó del Secretario General de la Sociedad de Naciones la convocatoria de una reunión del Consejo. La sesión tuvo lugar el 10 de diciembre. Los argumentos de Álvarez del Vayo descansaban en las previsibles consecuencias del desistimiento de aquella organización: «Lo peor para la Sociedad de Naciones es que ignorara o fingiera ignorar esta situación, y con ello se hiciese culpable, por silencio y pasividad, de la extensión probable de esta guerra que ahora padecemos nosotros solos». Subrayaba el bombardeo de ciudades abiertas, como el sufrido por Cartagena: «Sin el heroísmo del pueblo español, Italia y Alemania hubieran quizás conseguido dominar a España aprovechando la ocasión para apoderarse de las Baleares y otras bases navales, en el Mediterráneo o en el Atlántico. Este juego podría trasladarse luego a otros puntos. La solución final consistiría en ver a Europa pacificada enteramente por la supuesta acción bienhechora del fascismo internacional. Evidentemente, esta paz costaría la vida de millares de hombres, mujeres y niños, y numerosas capitales sufrirían la suerte de Alicante y Cartagena, pero oficialmente la paz no habría sido alterada» 39 .

La resolución adoptada - un ejercicio de diplomacia y de buenas palabras - no comprometía a nada ni a nadie. Recordaba la obligación de abstenerse de intervenir en 
los asuntos internos de España, recomendaba el respeto a los acuerdos de no intervención, sostenía la mediación de paz franco-británica y la ayuda humanitaria. Cartagena - al igual que el resto de la España republicana - continuó siendo hostigada. Como ha señalado $\mathrm{M}^{\mathrm{a}}$ Ángeles Egido, el comité además de ser una pura falacia, sirvió de coartada a la abstención de la Sociedad de Naciones ${ }^{40}$.

\section{El arte al servicio de la guerra: el caso de Luis Quintanilla}

La causa republicana consiguió aglutinar a lo más granado de la intelectualidad de la época. La cultura fue un arma más de combate, alentada por el Gobierno central, la Generalitat de Catalunya, los múltiples organismos nacidos al calor de la guerra Milicias de la Cultura, Guerrillas del Teatro, Altavoz del Frente - y desde los partidos y sindicatos ${ }^{41}$. Así se fraguó lo que se ha dado en llamar la Generación de la República, para otros la historia del arte que no pudo ser42. En este contexto - entre el arte y la propaganda - deben incluirse los dibujos realizados por Luis Quintanilla en 1937, algunos de ellos en Cartagena.

Luis Quintanilla Isasi (Santander 1893-Madrid 1978) está considerado como uno de fresquistas más importantes del momento, junto con Aurelio Arteta y Daniel Vázquez Díaz, cuando se asiste desde México al renacimiento de ésta técnica. Para López Sobrado, su mejor especialista, es el pintor cántabro con más valor histórico ${ }^{43}$. Su obra, como tantas otras, será sepultada por el franquismo. De formación autodidacta, compaginará la creación artística con el compromiso político: «A diferencia de los pintores vanguardistas de la época que practicaban el surrealismo o el neocubismo, a Quintanilla le costó poco convertirse en miliciano del arte y practicar el arte contra la guerra. Sin embargo, el compromiso político de Quintanilla no era el de un ideólogo,

$40 \quad$ EGIDO LEÓN, Ma ${ }^{\text {a }}$ Ángeles., «Relaciones internacionales de los dos bandos. La intervención extranjera en la guerra civil española», Cuenta y Razón, $\mathrm{n}^{0}$ 21, 1985.

$41 \quad$ GARCÍA I GARCÍA, Manuel, «Aproximación al arte español durante la guerra de 1936 a 1939", en La Guerra Civil española, Madrid, Ministerio de Cultura, 1980, p. 15; SORIA, Georges, Un éxito: el esfuerzo cultural, en Guerra y Revolución en España, 1936-1939, vol. V, Barcelona, Grijalbo, 1979, pp. 210-235; FERNÁNDEZ SORIA, Juan Manuel, Educación y cultura en la Guerra Civil (España 1936-39), Valencia, Nau Llibres, 1984; HUERTAS VÁZQUEZ, Eduardo, La política cultural de la Segunda República española, Madrid, Dirección General de Bellas Artes y Archivos, 1988; MAINER, José Carlos., Años de vísperas: la vida de la cultura en España (1931-1939), Madrid, Espasa-Calpe, 2006; ALTED VIGIL, Alicia., «La cultura como cauce de propaganda ideológica durante la guerra civil española (1936-1939)», Cuenta y Razón, $\mathrm{n}^{\mathrm{0}}$ 21, 1985.

$42 \quad$ SÁNCHEZ DÍAZ, Julián, «Entre la teoría y la historia: pensamiento artístico en el exilio español de 1939», Boletín del Museo e Instituto «Camón Aznar», XCII, 2003, p. 81.

43 Vid. QUINTANILLA, Luis, Pasatiempo. La vida de un pintor (Memorias), La Coruña, Ediciós do Castro, 2004; Edición, estudio introductorio y notas de Esther López Sobrado. 
sino el de un auténtico antifascista» 44. Es, ante todo, un hombre de acción, con una vida pletórica de experiencias, de giros y piruetas: marino, pintor, boxeador, torero accidental, dibujante, espía, autor teatral, ensayista, ilustrador de libros. De fuerte personalidad, como ha dejado constancia su amigo Luis Araquistáin: «... montañés arisco, temperamento indómito y pugnaz...». Hemingway, en prólogo a su libro All the Brave, se refiere a él como «... gran artista, hombre, soldado y revolucionario...».

A mediados de 1937, con el beneplácito del presidente Negrín, visitará los frentes y la retaguardia republicana, realizando una serie de dibujos que quieren reflejar los horrores de la guerra. Sus buenas conexiones le permitirán desplazarse por los diversos escenarios de la contienda, desde Almería a los Pirineos. Lo explica en sus memorias: «Negrín continuaba con el Gobierno en Valencia. Me preguntó por qué dejaba el servicio de la frontera y qué pensaba hacer. Se lo expliqué y le dije que quería recorrer todo el frente de guerra tomando apuntes para después realizar la exposición de los dibujos acabados y necesitaría, además del permiso especial del Gobierno, un automóvil y el conductor que lo cuidase. A Negrín le parecía bien la idea, considerando que sería un documento histórico y artístico...» 45.

Su periplo se prolongó durante dos meses. Estuvo en Granada y Córdoba, recaló en Madrid, pasó a Levante y erró de Cartagena a Cataluña. Su llegada a Cartagena coincidió con la celebración en Valencia del II Congreso Internacional de Escritores Antifascistas. A principios de julio de 1937 la situación en la base naval traducía la tensión por el control ideológico que anidaba en el bando republicano y que alcanzaba a las propias filas del Gobierno. El día 5, el comisario político de la Flota -Bruno Alonsocomunicaba a Prieto su firme posicionamiento: «Acaba de visitarme un representante del Ministerio de Instrucción Pública [su titular era Jesús Hernández del PCE], para que admita en la base y flota a los maestros encargados de las llamadas Milicias de la Cultura, a cuya autorización me he negado, mientras no me presenten alguna autorización expresa de V.». La fricción con el PCE era evidente: «...como aquí esa cultura es de los comunistas, el negarles la entrada excuso decirle el cariño que me tendrán, y que ya me tenían...». En el mismo escrito comentaba la presencia del dibujante santanderino: «...También estuvo aquí el pintor Quintanilla, que ha tomado algunos apuntes sin ninguna importancia» 46 .

44 GREEN, Jerald R., «El arte contra la guerra de Luis Quintanilla», Goya, nº 232, 1993, p. 218.

45 QUINTANILLA, Luis, Pasatiempo. La vida de un pintor, cit, p. 427.

$46 \quad$ AHN-SGC. Archivo de Bruno Alonso González. 
Prieto respaldó la decisión de Bruno con respeto a las Milicias de la Cultura, reafirmando su enfrentamiento con Jesús Hernández47. También mostró su contrariedad con relación a la visita de Quintanilla: «Por usted me entero de lo que son las Milicias de la Cultura. El ministro de Instrucción Pública no ha podido hacer lo que ha hecho sin consentimiento mío, pues no es él quien para ingerirse en forma alguna en los frentes, cuarteles, etc. Hasta ahora yo no he tenido noticia de semejante disposición. La conducta de usted sobre el particular, la apruebo. Me hubiera gustado que hubiese usted prohibido el acceso a los barcos del pintor Quintanilla. En los barcos no tienen que hacer nada, pintores, dibujantes ni cronistas, cualesquiera que sea su filiación política» ${ }^{48}$.

La empatía entre cántabros - Bruno Alonso era santanderino - y la afinidad política - los dos militaban en el PSOE -, debió permitir a Quintanilla completar su designio. Nos han llegado 13 de aquellos dibujos: ocho son estudios para su reelaboración posterior y cinco se corresponden con los publicados en el libro All the Braves $^{49}$. Dominan los marineros de la escuadra, con rostros de hombres curtidos, pero también de jóvenes combatientes, casi niños. En las cintas de los lepantos puede leerse Cartagena, Libertad y, curiosamente, Jaime I, que muy poco antes - el 17 de junio había quedado fuera de combate tras una terrible explosión interna50. Tal vez sea el homenaje del pintor. Figuran detalles de cuerpos musculados, firmes defensores de la República, y los inevitables tatuajes de las gentes de mar. Dejan constancia de la cotidianidad, representada en las horas de rancho y de reposo. Al margen de la marinería, tres escenas de la población civil: el desamparo de las mujeres y los niños y la vida en los refugios abiertos en la roca, entre el miedo y la miseria.

Están considerados - con la serie completa - como lo más logrado del pintor santanderino, caracterizados «por un patetismo realista y una verosimilitud bélica...», con referencias a la desolación y la barbarie, sin menospreciar su belleza espiritual y plástica. Son una apuesta por la ilustración objetiva de la guerra, huyendo de todo histerismo. Emparentados con los Desastres de la guerra de Goya, guardan similitudes con las obras de George Grosz y Max Beckmann. Están realizados en papel Imperial de Japón y su tamaño aproximado es de 11 1/2 x 17 pulgadas. Como escribiera Elliot, en su particular prólogo, «Si hay belleza en estas páginas, es porque la belleza es perversa e

47 Cfr. PRIETO, Indalecio, «Como y por qué salí del Ministerio de Defensa Nacional», en Convulsiones de España, vol. II, México, Oásis, 1967, pp. 38-39; HERNÁNDEZ, Jesús., Yo fui un ministro de Stalin, Madrid, G. Del Toro editor, 1974, p. 195.

$48 \quad$ AHN-SGC. Archivo de Bruno Alonso González.

49 Véase:

URL: < http://www.lqart.org/index.html > [consultado el 23/07/2011];

URL: < http://www.catrais.org/ > [consultado el 23/07/2011].

50 Vid. EGEA BRUNO, Pedro $\mathrm{M}^{\mathrm{a}}$, «Contribución al estudio de la flota republicana durante la guerra civil», cit. 
indestructible».

\section{Conclusiones}

Cartagena ocupó un lugar central en la defensa de la República. Su importante base naval y la constancia de una considerable guarnición de tierra, junto con su estratégico puerto y las industrias de guerra, la erigieron en objetivo preferente de la agresión militar del bando rebelde. En tales circunstancias, se hace preciso reforzar la moral de una población que vive la guerra en primera línea.

El horizonte de la propaganda se multiplicó. El frente de papel, la prensa en particular, asumió un carácter de combate abierto, donde los enemigos y las tareas a desarrollar quedaron claramente señalados. Se reconvirtieron las viejas cabeceras de las opciones de clase derrotadas y surgieron nuevas iniciativas, presididas - unas y otras - por la consigna, los llamamientos directos al compromiso de los jóvenes y la acerba crítica a los contrarios. A destacar los poemas de urgencia social de R. Perelló.

El espacio público fue utilizado para reafirmar el sentimiento de unidad, con las menciones ideológicas en presencia. Ocurrió en los sepelios de los combatientes caídos por la libertad y en la rotulación de calles, plazas públicas, barrios y diputaciones del término municipal. Nuevas y viejas referencias de la clase trabajadora tomaron cuerpo en el día a día de la convivencia ciudadana.

Los refugios antiaéreos se constituyeron en lugares de afinidad, armonizándose la búsqueda de seguridad con la agresión impune. El temor a los bombardeos alimentó el imaginario colectivo sobre el terror fascista. Las acciones más reiteradas - como el recordado bombardeo de las cuatro horas - llevaban la firma de la aviación italiana, cuyos submarinos también torpedearon el crucero Miguel de Cervantes. Ello alentó la difusión se folletos como el titulado Cartagena víctima del fascismo internacional. De este modo se asistió a la proyección exterior de la barbarie, aunque sólo obtuvo el silencio de la Sociedad de Naciones, cómplice del Comité de No Intervención.

La guerra, los gestos heroicos y el sufrimiento - como tantas otras veces - fueron transmutados en expresión estética. El genio de Luis Quintanilla permitió perpetuar la actitud de anónimos protagonistas de la marina leal - la escuadra en sí - y escenas cotidianas de una ciudad asediada.

Tras la derrota, las señas testimoniales del bando republicano - la memoria histórica democrática - fueron borradas por la represión, el miedo y la imposición ideológica de los vencedores. Hoy día, la tarea de su reconstrucción sigue siendo una labor pendiente en 


\section{* El autor}

Pedro $M^{\mathrm{a}}$ Egea Bruno es Catedrático de Historia Contemporánea en la Universidad de Murcia. Pertenece a diferentes asociaciones y entidades científicas. Es Académico Correspondiente por Murcia de la Real Academia de la Historia. Su labor investigadora se ha traducido hasta el momento en un centenar de artículos en revistas científicas y 57 libros sobre temas de su especialidad, entre los que destacan: El distrito minero de Cartagena en torno a la Primera Guerra Mundial (1909-1923); La represión franquista en Cartagena (1939-1945); La política y los políticos en la Cartagena de Alfonso XIII (1902-1923); Apuntes para la historia del movimiento obrero en la industria naval de Cartagena (1898-1923); Cartagena. Imagen y memoria, una historia gráfica en cuatro tomos, y La enseñanza primaria en Cartagena durante la II República y la Guerra Civil (1931-1939). Es coautor - con Juan B. Vilar y Diego Victoria de La minería murciana contemporánea I (1840-1930) y II (1930-1985) y de El movimiento obrero en el distrito minero de Cartagena-La Unión (1840-1930). A él corresponde el estudio de la Edad Contemporánea en la obra colectiva Manual de Historia de Cartagena. En la actualidad su obra se centra en II República, Guerra Civil y etapa franquista, avanzando en estudios sobre la economía, la política, la ideología, la cultura, la vida cotidiana, las emigraciones y la mujer.

URL: < http://studistorici.com/progett/autori/\#EgeaBruno >

\section{Per citare questo articolo:}

EGEA BRUNO, Pedro $\mathrm{M}^{\mathrm{a}}$, «Cultura de resistencia y guerra civil en la base naval principal de la República. Cartagena (1936-1939)», Diacronie. Studi di Storia Contemporanea: Spagna Anno Zero: la guerra come soluzione, 29/07/2011,

URL:< http://www.studistorici.com/2011/07/29/egea_numero_7 >

Diacronie Studi di Storia Contemporanea $\vartheta$ www.diacronie.it

Risorsa digitale indipendente a carattere storiografico. Uscita trimestrale. redazione.diacronie@hotmail.it

Comitato di redazione: Marco Abram - Giampaolo Amodei - Jacopo Bassi - Luca Bufarale - Alessandro Cattunar - Alice De Rensis Barbara Galimberti - Deborah Paci - Fausto Pietrancosta - Martina Sanna - Matteo Tomasoni - Luca Zuccolo

Diritti: gli articoli di Diacronie. Studi di Storia Contemporanea sono pubblicati sotto licenza Creative Commons 2.5 . Possono essere riprodotti a patto di non modificarne i contenuti e di non usarli per fini commerciali. La citazione di estratti è comunque sempre autorizzata, nei limiti previsti dalla legge. 